\title{
Comparison of MammaPrint and TargetPrint results with clinical parameters in German patients with early stage breast cancer
}

\author{
HEIDRUN GEVENSLEBEN ${ }^{1}$, UWE-JOCHEN GÖHRING ${ }^{2}$, REINHARD BÜTTNER ${ }^{1}$, \\ LUKAS C. HEUKAMP ${ }^{1}$, GEORG KUNZ ${ }^{3}$, THOMAS DIMPFL ${ }^{4}$, CHRISTIAN JACKISCH ${ }^{5}$, \\ OLAF ORTMANN $^{6}$, UTE-SUSANN ALBERT ${ }^{7}$, RICHARD BENDER ${ }^{8}$, FEMKE DE SNOO ${ }^{9}$, \\ OSCAR KRIJGSMAN ${ }^{10}$, ANNUSKA M. GLAS ${ }^{10}$, YAVUZ H. ERGÖNENC ${ }^{11}$, CORINNA VOGEL $^{12}$, \\ AUGUST DYKGERS ${ }^{13}$, CLAUS LANGWIEDER ${ }^{13}$, MARTIN REES ${ }^{13}$ and TOBIAS ANZENEDER ${ }^{14}$ \\ ${ }^{1}$ Institute of Pathology, University Hospital Bonn; ${ }^{2}$ Johanniter Hospital, Bonn; ${ }^{3}$ Department of Obstetrics and \\ Gynaecology, St. Johannes Hospital Dortmund, Dortmund; ${ }^{4}$ Department of Obstetrics and Gynaecology, \\ Klinikum Kassel, Kassel; ${ }^{5}$ Department of Obstetrics and Gynaecology, Klinikum Offenbach GmbH, \\ Offenbach; ${ }^{6}$ Department of Gynaecology and Obstetrics, University Hospital Regensburg, Regensburg; \\ ${ }^{7}$ Gynecological Endocrinology and Oncology, University of Marburg, Marburg, Germany; ${ }^{8}$ Medical Affairs, \\ Agendia, Huntington Beach, CA, USA; ${ }^{9}$ Medical Affairs and ${ }^{10}$ Research and Development, Agendia, \\ Amsterdam, The Netherlands; ${ }^{11}$ Cooperative Breastcenter, St. Anna Hospital Herne, Herne; \\ ${ }^{12}$ Institute of Pathology, University of Regensburg, Regensburg; ${ }^{13}$ Institute of Pathology \\ at Josefshaus, Dortmund; ${ }^{14}$ Patients Tumor Bank of Hope (PATH), Germany
}

Received June 9, 2010; Accepted July 30, 2010

DOI: 10.3892/ijmm_00000532

\begin{abstract}
The 70-gene expression profile MammaPrint is a powerful prognostic indicator for disease outcome in breast cancer patients with improved prediction of recurrence risk compared to currently used guidelines. The microarraybased test TargetPrint further provides reliable, quantitative assessment of mRNA expression levels of estrogen receptor $(\mathrm{ER})$, progesterone receptor $(\mathrm{PR})$ and human epidermal growth factor receptor 2 (HER2). This study was performed as a validation of MammaPrint and TargetPrint in an unselected German breast cancer population and was designed to determine the degree of concordance with currently applied clinical parameters. One hundred and forty cases of breast cancer stage I and II were classified as being low or high risk for distant metastasis using MammaPrint. Results were compared to current clinical risk classifications and adjuvant treatment management. Immunohistochemistry (IHC) and fluorescent in situ hybridization (FISH)/chromogenic in situ hybridization (CISH) assessments of ER, PR and HER2 were further compared with gene expression read-outs using
\end{abstract}

Correspondence to: Dr Heidrun Gevensleben, Institute of Pathology, University Hospital Bonn, Sigmund-Freud-Strasse 25, D-53127 Bonn, Germany

E-mail: heidrun.gevensleben@ukb.uni-bonn.de

Key words: breast cancer, MammaPrint, 70-gene expression profile, TargetPrint, microarray, adjuvant therapy
TargetPrint. Thirty-two percent of patients (19/59) with a poor prognosis-signature identified via MammaPrint did not receive adjuvant systemic treatment apart from endocrine therapy and were potentially undertreated; whereas $42 \%(35 / 77)$ of patients with a good prognosis-signature received chemotherapy and were potentially overtreated. Comparison of microarray receptor results with IHC and FISH/CISH were concordant in 97\% for ER; $86 \%$ for PR; and 94\% for HER2. In this German study population, MammaPrint would have resulted in altered treatment advice for adjuvant systemic therapy in $40 \%$ of patients. Furthermore, TargetPrint presented high concordance for ER, PR and Her2 with IHC and FISH/CISH analysis.

\section{Introduction}

The mortality of breast cancer in Western countries is constantly decreasing due to effective treatment options (1). Adjuvant systemic therapy substantially improves diseasefree and overall survival in both premenopausal and postmenopausal women with lymph node negative or lymph node positive breast cancer $(2,3)$. Currently, the decision on adjuvant treatment for breast cancer patients is based on risk assessments using clinicopathological criteria (i.e. age, tumour size, status of axillary lymph nodes, histologic tumour subtype, pathological grade, and hormone receptor status). However, patients with similar tumour characteristics can have strikingly different disease outcomes, reflecting the heterogeneity of breast cancer. Thus, for risk assessment additional parameters are required to avoid both under- and overtreatment. 
Systematic analysis of gene expression patterns using microarray technology has led to the discovery of prognostic gene expression signatures, one of which is the 70-gene prognostic signature MammaPrint (4). Subsequent studies have validated the prognostic value of the 70 -gene profile in early stage breast cancer patients with either node-positive or node-negative disease (5-8). It was confirmed that the 70-gene signature discriminates between patients at high risk of distant metastasis and patients with a favourable prognosis. Furthermore, the 70-gene signature was shown to add independent prognostic information to that provided by commonly used clinicopathological factors. Although the custom-designed array chip MammaPrint was originally designed to identify younger breast cancer patients at low risk for distant metastasis, the same signature was validated in an older patient cohort showing a very high negative predictive value for distant recurrence after adjuvant treatment $(9,10)$. As a result, patients with a good prognosis and a low risk of developing distant metastasis may be spared adjuvant systemic treatment and its associated toxicity $(4,8,11)$. At present, these issues are being addressed in the MINDACT trial, a prospective, multicenter, clinical trial in Europe (12).

In our study, we further evaluated TargetPrint, a new diagnostic test providing the precise molecular read-out of standard prognostic factors. TargetPrint quantitatively determines gene expression levels of the estrogen receptor (ER), progesterone receptor (PR) and human epidermal growth factor receptor 2 (HER2) in breast cancer tumours. At present, a high percentage of inconsistent results are being reported for the assessment of hormone receptors and HER2 via immunohistochemistry (IHC) $(13,14)$. The microarraybased read-out TargetPrint relies on controlled and objective quantification of receptor mRNA levels showing a high concordance with IHC, as well as fluorescence in situ hybridization (FISH) or chromogenic in situ hybridisation (CISH) assessments. Concordant results between TargetPrint and IHC/CISH were detected in $93 \%$ for ER and $96 \%$ for HER2 (15) indicating that this method provides accurate measurement of important prognostic factors and, therefore, is a reliable addition to current techniques.

With the emergence of gene expression analysis as a promising tool for the prediction of disease outcome and therapeutic decisions, a number of authors have emphasized critical issues on the use of microarray data. Matters such as gene selection bias, error estimation and fragility of gene signatures have been discussed (16-18). Moreover, questions have arisen if gene signatures will add prognostic value to that provided by the risk classification based on standard clinicopathological factors (19-21). Therefore, the recently proposed gene signatures need to be validated independently, preferably by teams external to the original institutions, using prospectively defined criteria.

Our study was set up to validate MammaPrint and TargetPrint in an unselected German patient population using samples from the 'Patients Tumor bank of Hope' (PATH), a unique tumour bank established by the breast cancer initiative 'Mamazone' (http://www.mamazone.de). The objectives of our study were: i) to analyze the concordance between the 70-gene profile and the risk estimation based on clinicopathological parameters, and ii) to validate TargetPrint as a quantitative assessment of the expression of hormone receptors and HER2.

\section{Materials and methods}

Patients. A total of 170 frozen tumour samples from women who had been consecutively diagnosed with breast cancer stage I and II between 2005 and 2008 were selected from the 'Patients Tumour bank of Hope' (PATH). This tumour bank initiated by the German breast cancer patient group 'Mamazone' represents the first fresh frozen tumour tissue bank founded and owned by cancer patients to provide cryopreservation of tumour samples. All patients had been treated by modified radical mastectomy or breast-conserving surgery, including dissection of axillary lymph nodes and followed by radiotherapy, if indicated. Biopsies of the primary tumour were snap-frozen and either stored in the gas phase above liquid nitrogen at $-196^{\circ} \mathrm{C}$ or alternatively at $-152^{\circ} \mathrm{C}$ in low temperature deep freezers. All patients from whom adequate RNA could be extracted from the tumour samples were included in the study. The study was approved by local and regional ethics committees. All participants gave written informed consent.

Histopathological data, patient demographics and therapy information were available through PATH. Tumour grading was defined according to the Elston and Ellis method (22). ER and PR status were determined by immunohistochemistry and interpreted as positive if $>10 \%$ of the nuclei stained positive. HER2 status was assessed by scoring the intensity of membrane staining using immunohistochemistry. Tumours with a score of $3+$ (strong homogeneous staining) were considered HER2-positive. In case of 2+ scores (moderate homogeneous staining) either CISH or FISH was used to determine amplification (23). Amplification was defined as a gene copy number of over five copies per cell.

Microarray expression profiling. RNA labelling, microarray hybridization and scanning were performed at Agendia. RNA was co-hybridised with a standard reference to the customdesigned array chip MammaPrint consisting of eight identical subarrays, each containing oligonucleotide probes for the 70 genes in triplicate (11). Tumours were classified using the previously reported 70-gene classification model (4) and were defined as having a low-risk gene signature if the correlation coefficient was above the set threshold. All other cases were assigned to the high-risk group. According to the previously established classifier, good prognosis was defined as a probability of a 10-year distant metastasis-free survival of $>90 \%$ (6).

Clinical risk classification. The prognostic value of the 70-gene signature was assessed in comparison with the St. Gallen criteria defining three risk categories; lower risk node-negative disease and intermediate and higher risk node-positive disease (24). Referring to the 9th St. Gallen Consensus Meeting in 2005 , criteria also included the size of primary tumour, age, histological grade, hormone receptor status, peritumoral vascular invasion and HER2 status. However, as the majority of patients were classified as intermediate risk according to 
Table I. Clinicopathologic features of patients classified as high or low risk for distant metastasis using MammaPrint.

\begin{tabular}{|c|c|c|c|c|}
\hline & $\begin{array}{c}\text { Total } \\
\mathrm{n}=140\end{array}$ & $\begin{array}{c}\text { MammaPrint } \\
\text { Good } \\
\text { prognosis } \\
\mathrm{n}=78(\%)\end{array}$ & $\begin{array}{c}\text { MammaPrint } \\
\text { Poor } \\
\text { prognosis } \\
\mathrm{n}=62(\%)\end{array}$ & $\mathrm{P}$-value \\
\hline \multicolumn{5}{|l|}{ Age (years) } \\
\hline$<36$ & 2 & $1(1)$ & $1(2)$ & \\
\hline $36-45$ & 16 & $11(14)$ & $5(8)$ & \\
\hline $46-55$ & 29 & $17(22)$ & $12(19)$ & \\
\hline$>55$ & 93 & $49(63)$ & $44(71)$ & \\
\hline \multicolumn{5}{|l|}{ Histology } \\
\hline Ductal & 108 & $59(76)$ & $49(79)$ & 0.635 \\
\hline Lobular & 23 & $12(15)$ & $11(18)$ & 0.708 \\
\hline Other & 9 & $7(9)$ & $2(3)$ & \\
\hline \multicolumn{5}{|l|}{ Grade } \\
\hline Good & 14 & $11(14)$ & $3(5)$ & \\
\hline Intermediate & 88 & $58(74)$ & $30(48)$ & \\
\hline Poor & 38 & $9(12)$ & $29(47)$ & $<0.001^{\mathrm{b}}$ \\
\hline \multicolumn{5}{|l|}{ Stage } \\
\hline I & 50 & $35(45)$ & $15(24)$ & $0.011^{\mathrm{a}}$ \\
\hline IIa & 56 & $27(35)$ & $29(47)$ & \\
\hline IIb & 32 & $15(19)$ & $17(27)$ & \\
\hline IIIa & 1 & $0(0)$ & $1(2)$ & \\
\hline IIIb & 1 & $1(1)$ & $0(0)$ & \\
\hline \multicolumn{5}{|l|}{ Tumour size } \\
\hline$\leq 1 \mathrm{~cm}$ & 7 & $4(5)$ & $3(5)$ & \\
\hline$>1 \mathrm{~cm} \leq 2 \mathrm{~cm}$ & 57 & $39(50)$ & $18(29)$ & \\
\hline$>2 \mathrm{~cm} \leq 5 \mathrm{~cm}$ & 72 & $34(44)$ & $38(61)$ & \\
\hline$>5 \mathrm{~cm}$ & 4 & $1(1)$ & $3(5)$ & $0.005^{\mathrm{a}}$ \\
\hline \multicolumn{5}{|l|}{$\begin{array}{l}\text { Lymph node } \\
\text { status }\end{array}$} \\
\hline Positive & 46 & $24(31)$ & $22(35)$ & 0.555 \\
\hline Negative & 94 & $54(69)$ & $40(65)$ & \\
\hline \multicolumn{5}{|l|}{ ER } \\
\hline Positive & 116 & 77 (99) & $39(63)$ & \\
\hline Negative & 24 & $1(1)$ & $23(37)$ & $<0.001^{\mathrm{b}}$ \\
\hline \multicolumn{5}{|l|}{ PR } \\
\hline Positive & 98 & $68(87)$ & $30(48)$ & \\
\hline Negative & 42 & $10(13)$ & $32(52)$ & $<0.001^{\mathrm{b}}$ \\
\hline \multicolumn{5}{|l|}{ HER2 } \\
\hline Positive & 9 & $3(4)$ & $6(9)$ & 0.183 \\
\hline Negative & 129 & $74(95)$ & $55(89)$ & \\
\hline Unknown & 2 & $1(1)$ & $1(2)$ & \\
\hline
\end{tabular}

a $\mathrm{P}<0.01,{ }^{\mathrm{b}} \mathrm{P}<0.001$

the St. Gallen criteria, the clinical risk of developing distant metastases was additionally assessed using the recently introduced Adjuvant! software (http://www.adjuvantonline. com) (25). Adjuvant!Online is being increasingly used in routine clinical practice as a tool for treatment decisions. This software calculates population-based estimates of a patient's 10-year relapse risk based on clinicopathologic information. Input variables include age, ER status, nodal status, tumour size and histological grade. In a recent external validation, Adjuvant! software was shown to predict overall survival, breast cancer specific survival and event-free survival in women diagnosed with early breast cancer (26) with high accuracy.

Statistical analysis. Analyses were performed using SPSS version 15.1 (SPSS Inc, Chicago, IL). The differences in patient and tumour characteristics between the MammaPrint poor and good prognosis-signatures were tested using the Pearson Chi-square or Fisher's exact probability test.

\section{Results}

Clinical characteristics. A total of 170 samples were collected from the German tumour bank 'PATH' with 26 samples ineligible for gene expression profiling, as they contained too few tumour cells. Of the remaining 144 patients, four samples had insufficient RNA quality and 140 (97\%) were successfully hybridized. Clinicopathological characteristics are given in Table I. Among the 140 patients analyzed with MammaPrint, $78(56 \%)$ had a good prognosis-signature, whereas $62(44 \%)$ patients displayed a poor prognosis-signature (Fig. 3). Median age at surgery was 62.5 years (range: 33-88 years). Tumours with a poor prognosis-signature were more often associated with a larger tumour size $(66 \%$ vs. $45 \%>2 \mathrm{~cm}$; $\mathrm{p}=0.005)$ and a high histological grade (G3) (47\% vs. 12\%; $\mathrm{p}<0.001)$. However, 9 out of 38 poorly differentiated tumours (24\%) still had a good prognosis according to MammaPrint. Further, tumours with a poor prognosis-signature were significantly more often classified as ER negative (37\% vs. $1 \% ; \mathrm{p}<0.001)$ and PR negative $(52 \%$ vs. $13 \% ; \mathrm{p}<0.001)$. Patients with a good prognosis-signature tended to be more often diagnosed with breast cancer stage I ( $45 \%$ vs. $24 \%$; $\mathrm{p}=0.011$ ). There was no difference in percent comparing poor with good prognosis patients with lymph node metastases (35\% vs. $31 \% ; p=0.555)$. Notably, however, a large proportion of patients with lymph node positive status $(24 / 46,52 \%)$, which would have been classified as poor prognosis-cases according to clinical para-meters, were found to have a good prognosis-signature. No difference was seen according to the histological tumour subtype or HER2 status.

Concordance of risk assessment. MammaPrint profiles for the St. Gallen risk groups are depicted in Fig. 1A. The majority of patients $(n=123)$ were classified as intermediate risk by St. Gallen. Of these $43 \%$ (53/123) were reclassified as having a poor prognosis by MammaPrint, whereas 57\% (70/123) had a good prognosis. Two of the ten patients classified as St. Gallen high risk had a good prognosis using the 70-gene prognostic signature. In addition, one case in the St. Gallen low risk group $(n=7)$ had a poor prognosis-signature by MammaPrint. Comparing the MammaPrint results with the risk classification determined by Adjuvant!Online revealed discordance in 57 of 140 (41\%) of patients (Fig. 1B). Forty-five patients $(47 \%)$ in the Adjuvant!Online high risk group $(n=95)$ had a good prognosis using the MammaPrint while 12 patients $(27 \%)$ of the Adjuvant!Online low risk group ( $n=45)$ were classified as having a poor prognosis by MammaPrint. 
A

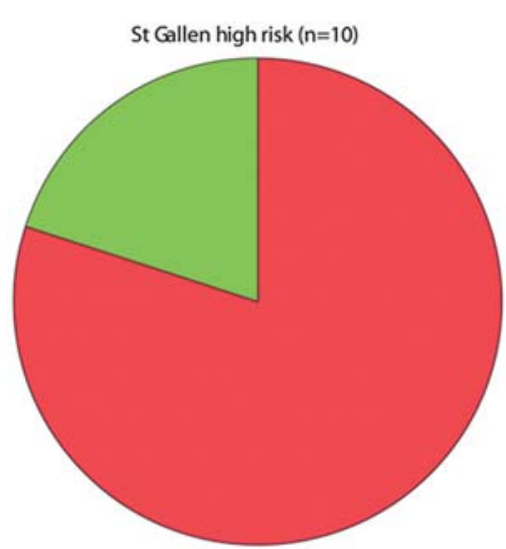

2/10 MammaPrint good prognosis

St Gallen intermediate risk $(n=123)$

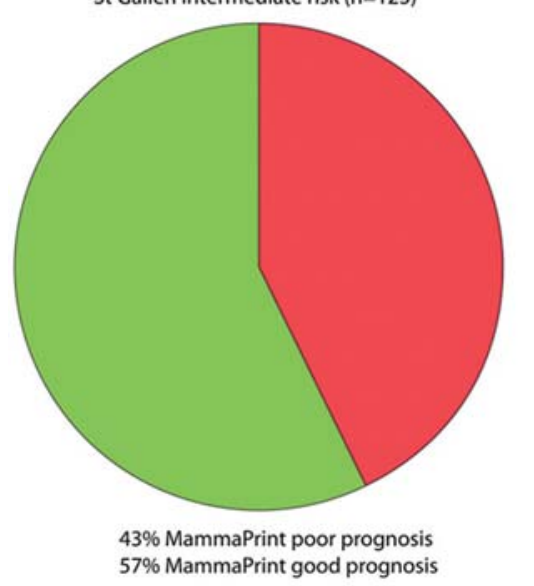

B

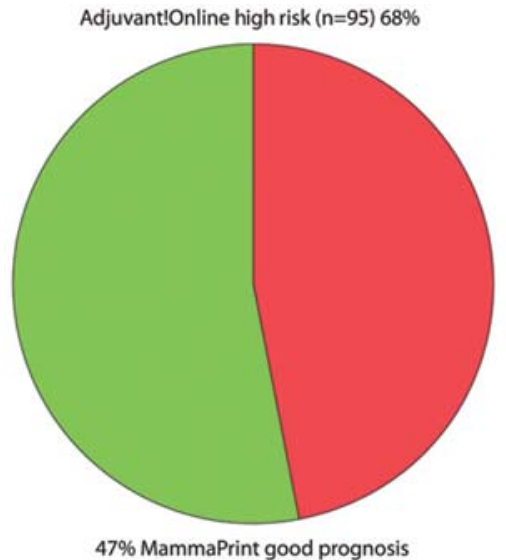

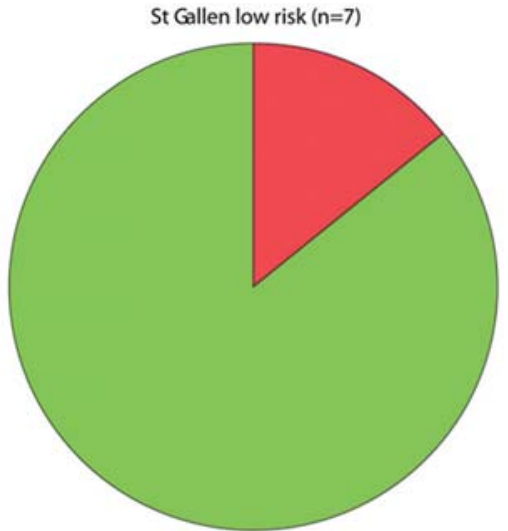

1/7 MammaPrint poor prognosis

MammaPrint good prognosis

MammaPrint poor prognosis

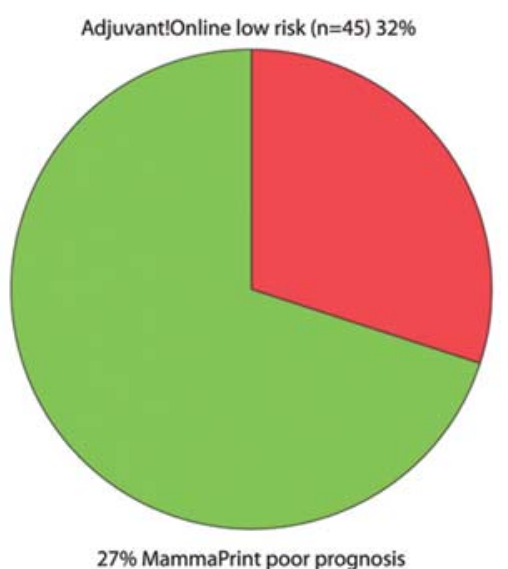

Figure 1. Concordance of risk assessment. The majority of patients were classified as intermediate risk according to the St. Gallen criteria. MammaPrint profiles for the St. Gallen risk groups are depicted (A). Comparison of MammaPrint results with the risk classification by Adjuvant!Online revealed discordance in $41 \%$ of patients (B).

Treatment advice. The 70-gene profile was analyzed in 140 patients of whom 134 received adjuvant systemic therapy. The particular therapy schemes consisted of chemotherapy $(23 / 134$; $17 \%)$, endocrine therapy $(59 / 134 ; 44 \%)$, or both $(52 / 134$; $39 \%)$. Two patients did not receive any adjuvant systemic therapy and in four cases further treatment remained unknown. Actual treatment and clinical and gene signature risk classifications are presented in Table II. For 59 out of 62 patients with a poor prognosis-signature identified by MammaPrint, the clinical treatment was recorded. Nineteen of these patients
(32\%) did not receive adjuvant systemic treatment other than endocrine therapy and were potentially undertreated. In contrast, 35 out of 77 patients (45\%) that were classified as having a good prognosis by MammaPrint and for whom treatment was known received chemotherapy and were potentially overtreated. Thus, using MammaPrint would have resulted in altered treatment advice in $40 \%$ of patients.

Microarray-based receptor read-out. The expression levels of ER, PR and HER 2 were determined using microarray analysis, 


\begin{tabular}{|c|c|c|c|}
\hline \multirow{2}{*}{ PATH } & \multicolumn{3}{|c|}{ IHC } \\
\hline & pos & neg & total \\
\hline pos & 114 & 2 & 116 \\
\hline neg & 2 & 22 & 24 \\
\hline$\overline{0}$ & pos & neg & total \\
\hline pos & 86 & 12 & 98 \\
\hline 氖 & 8 & 34 & 42 \\
\hline 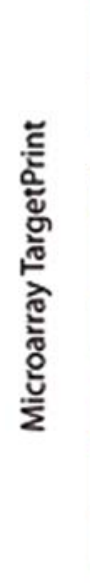 & pos & neg & total \\
\hline pos & 7 & 2 & 9 \\
\hline neg & 6 & 123 & 129 \\
\hline
\end{tabular}

Figure 2. Microarray based receptor read-out. Comparison of microarray receptor results with $\mathrm{IHC} / \mathrm{FISH}$ indicating highly similar results with a concordance of $97 \%$ for ER, $86 \%$ for PR and $94 \%$ for HER2. Two samples that were IHC $2^{+}$and not scored by FISH, were both classified as negative by TargetPrint.

which has been shown to be a reliable assay for the assessment of receptor status (4). As a result, 114 ER-positive tumours,
86 PR-positive cases and 7 HER2-positive tumours were identified in our patient cohort (Fig. 2). Comparison of microarray receptor results between IHC and FISH/CISH performed at the local hospitals in Germany indicated similar results with a concordance of $97 \%$ for ER; $86 \%$ for PR; and $94 \%$ for HER2. Two samples that were IHC $2^{+}$for HER2 and not scored by FISH, were both classified as negative by TargetPrint.

\section{Discussion}

The 70-gene signature MammaPrint has been retrospectively validated as a prognostic tool, showing that early stage breast cancer patients can be molecularly stratified $(6,8)$. Combined with clinical risk profiling MammaPrint represents a valuable tool to more accurately identify patients who might be spared adjuvant chemotherapy with its associated toxic side effects. However, many breast cancer patients are older than the cohorts initially selected in previous validation studies $(6,8)$. It was demonstrated, that although the MammaPrint assay was originally designed to identify younger breast cancer patients at low risk for distant metastasis, the same signature had a very high negative predictive value for distant recurrence after adjuvant treatment in older breast cancer patients $(9,10)$.

In this study, a series of 140 patients with stage I and II primary invasive breast cancer (who predominantly received systemic adjuvant therapy) was analyzed. This study reflects

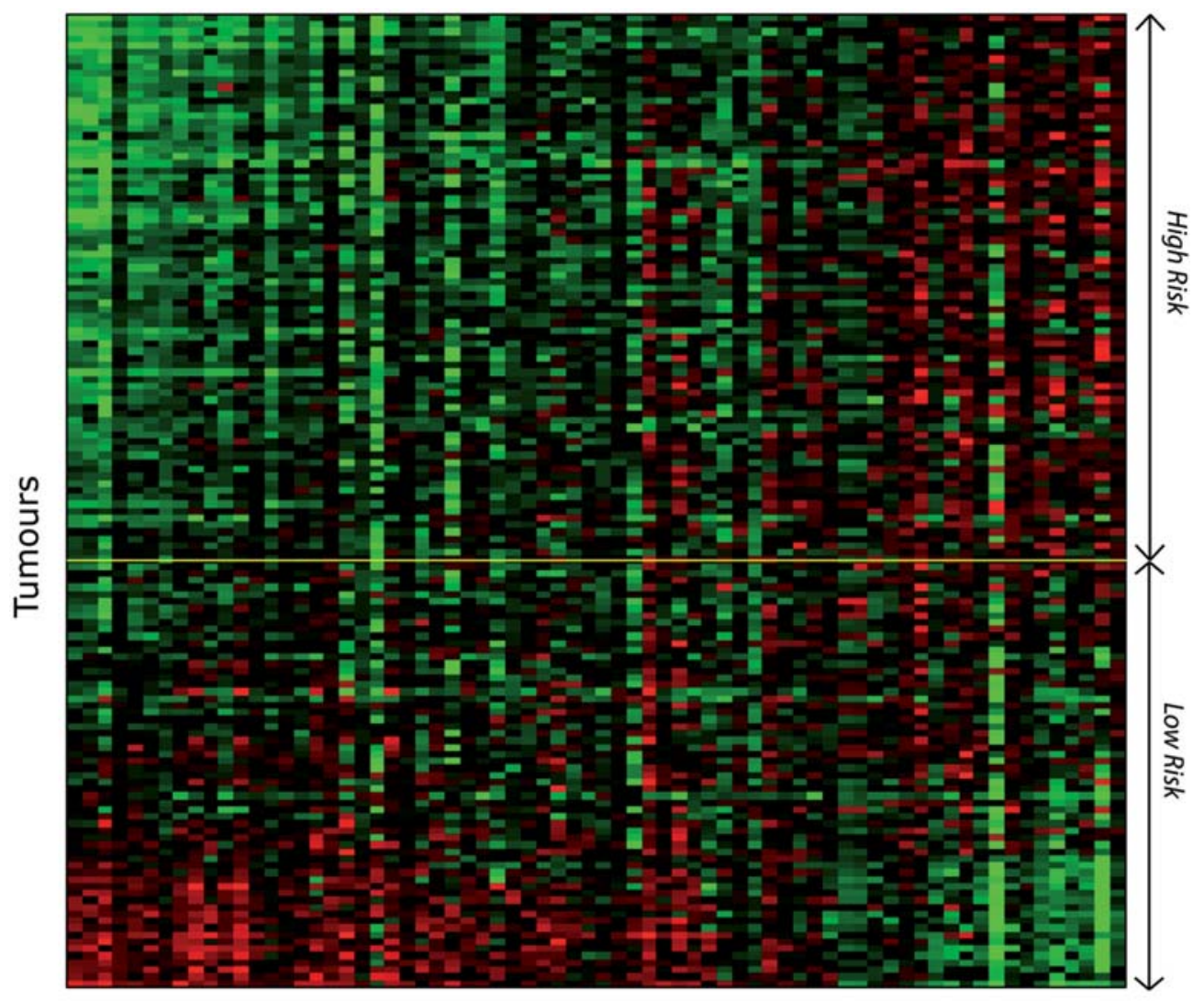

MammaPrint genes

Figure 3. Gene expression pattern. Expression data matrix of the 70 prognostic marker genes in a series of 140 breast cancer patients hybridized using MammaPrint. Each row represents the prognostic profile of one tumour and each column the relative expression level of one gene. The cut-off between good prognosis and poor prognosis-signature is marked with a yellow line. The tumours are ordered by their correlation to the MammaPrint template. 
Table II. Actual treatment, clinical and gene signature risk classifications.

\begin{tabular}{|c|c|c|c|c|c|c|c|c|}
\hline & $\begin{array}{l}\text { Actual } \\
\text { treatment }\end{array}$ & $\begin{array}{l}\text { MammaPrint } \\
\text { poor prognosis }\end{array}$ & $\begin{array}{l}\text { MammaPrint } \\
\text { good prognosis }\end{array}$ & $\begin{array}{l}\text { St. Gallen } \\
\text { high risk }\end{array}$ & $\begin{array}{l}\text { St. Gallen } \\
\text { intermediate risk }\end{array}$ & $\begin{array}{l}\text { St. Gallen } \\
\text { low risk }\end{array}$ & $\begin{array}{l}\text { Adjuvant! } \\
\text { high risk }\end{array}$ & $\begin{array}{c}\text { Adjuvant! } \\
\text { low risk }\end{array}$ \\
\hline No treatment & 2 & 0 & 2 & 0 & 2 & 0 & 1 & 1 \\
\hline $\mathrm{ET}^{\mathrm{a}}$ & 59 & 19 & 40 & 1 & 52 & 6 & 28 & 31 \\
\hline $\mathrm{CT}^{\mathrm{b}}$ & 23 & 19 & 4 & 7 & 16 & 0 & 22 & 1 \\
\hline CT plus ET & 52 & 21 & 31 & 0 & 51 & 1 & 40 & 12 \\
\hline Unknown & 4 & 3 & 1 & 2 & 2 & 0 & 4 & 0 \\
\hline Total & 140 & 62 & 78 & 10 & 123 & 7 & 95 & 45 \\
\hline
\end{tabular}

${ }^{\mathrm{a} E n d o c r i n e}$ therapy; ${ }^{\mathrm{b}}$ chemotherapy.

a representative cohort of patients as seen in clinical practice with a median age of 62.5 years. We additionally accessed both positive and negative lymph node patients for our analysis. According to MammaPrint results, the proportion of tumours with a good 70-gene prognosis-signature was $56 \%$, whereas $44 \%$ of the tumours had a poor prognosis-signature. The percentage of tumours with a good 70-gene prognosissignature was higher than reported in earlier studies $(37 \%$ and $39 \%)(6,8)$, yet similar to that reported in more recent studies $(51 \%$ and $52 \%)(5,27)$.

Tumours with a poor prognosis-signature were more often associated with a high histological grade and a larger tumour size. Further, they were more often classified as ER negative and PR negative, indicating that established clinical risk factors are reflected in the array data. On the other hand, breast cancer cases with a good prognosis-signature tended to be more often diagnosed with stage I disease. However, 24 of 46 tumours with lymph node metastases (52\%) that would have been classified as having a poor prognosis using clinicopathological criteria were identified as having a good prognosis-signature according to MammaPrint results.

Although our findings concurred with the clinical risk assessment to a certain degree, the comparison of MammaPrint results with the risk classification by Adjuvant!Online were discordant and consequently lead to a different treatment advice in $40 \%$ of patients. MammaPrint-based classification therefore provides additional information to Adjuvant!Onlinebased risk determination which includes standard prognostic markers (i.e. age, tumour size, status of axillary lymph nodes, histological grade, and hormone-receptor status). Although at present we have no possibility of providing confirmatory follow-up data for the outcome of the patients analyzed in this study, we nevertheless suggest, that these findings are highly relevant regarding risk stratification and treatment advice.

TargetPrint, a new diagnostic test providing the single gene read-out of standard prognostic markers, was additionally analyzed in our series of patients. TargetPrint was introduced as an additive tool for receptor assessment to address inconsistent results reported for the assessment of hormone receptors and HER2 via IHC $(13,14)$. Our results revealed a high concordance of $97 \%$ for ER; $86 \%$ for PR; and $94 \%$ for HER2 compared with IHC and FISH/CISH performed at the local hospitals. Thus, Target-Print proved to be a reliable addition to current techniques providing accurate measurement of ER, PR and HER2 expression.

In conclusion, the 70-gene prognostic signature MammaPrint has been validated in multiple breast cancer populations and was shown to provide improved prediction of recurrence risk compared with currently used guidelines. In this German study population, MammaPrint would have resulted in altered treatment advice for adjuvant systemic therapy in $40 \%$ of patients. Furthermore, the application of TargetPrint in the same cohort demonstrated high concordance of microarraybased receptor read-out with IHC and FISH/CISH results verifying this test as a reliable tool for the assessment of standard prognostic factors.

\section{References}

1. EBCTCG: Effects of chemotherapy and hormonal therapy for early breast cancer on recurrence and 15-year survival: an overview of the randomised trials. Lancet 365: 1687-1717, 2005.

2. EBCTCG: Polychemotherapy for early breast cancer: an overview of the randomised trials. Early Breast Cancer Trialists' Collaborative Group. Lancet 352: 930-942, 1998.

3. EBCTCG: Tamoxifen for early breast cancer: an overview of the randomised trials. Early Breast Cancer Trialists' Collaborative Group. Lancet 351: 1451-1467, 1998.

4. van't Veer LJ, Dai H, van de Vijver MJ, et al: Gene expression profiling predicts clinical outcome of breast cancer. Nature 415: 530-536, 2002.

5. Bueno-de-Mesquita JM, van Harten WH, Retel VP, et al: Use of 70-gene signature to predict prognosis of patients with nodenegative breast cancer: a prospective community-based feasibility study (RASTER). Lancet Oncol 8: 1079-1087, 2007.

6. Buyse M, Loi S, van't Veer L, et al: Validation and clinical utility of a 70-gene prognostic signature for women with nodenegative breast cancer. J Natl Cancer Inst 98: 1183-1192, 2006.

7. Mook S, Schmidt MK, Viale G, et al: The 70-gene prognosissignature predicts disease outcome in breast cancer patients with 1-3 positive lymph nodes in an independent validation study. Breast Cancer Res Treat 116: 295-302, 2009.

8. van de Vijver MJ, He YD, van't Veer LJ, et al: A gene-expression signature as a predictor of survival in breast cancer. $\mathrm{N}$ Engl $\mathrm{J}$ Med 347: 1999-2009, 2002.

9. Wittner BS, Sgroi DC, Ryan PD, et al: Analysis of the MammaPrint breast cancer assay in a predominantly postmenopausal cohort. Clin Cancer Res 14: 2988-2993, 2008.

10. Mook S, et al: The 70-gene MammaPrint prognosis signature predicts early metastases in older breast cancer patients. Ann Oncol 21: 717-722, 2010.

11. Glas AM, Floore A, Delahaye LJ, et al: Converting a breast cancer microarray signature into a high-throughput diagnostic test. BMC Genomics 7: 278, 2006. 
12. Bogaerts J, Cardoso F, Buyse M, et al: Gene signature evaluation as a prognostic tool: challenges in the design of the MINDACT trial. Nat Clin Pract Oncol 3: 540-551, 2006.

13. Thomson TA, Hayes MM, Spinelli JJ, et al: HER-2/neu in breast cancer: interobserver variability and performance of immunohistochemistry with 4 antibodies compared with fluorescent in situ hybridization. Mod Pathol 14: 1079-1086, 2001.

14. Regitnig P, Reiner A, Dinges HP, et al: Quality assurance for detection of estrogen and progesterone receptors by immunohistochemistry in Austrian pathology laboratories. Virchows Arch 441: 328-334, 2002.

15. Roepman P: Microarray based determination of ER, PR and HER2 receptor status in breast cancer. Clin Cancer Res (In press).

16. Michiels S, Koscielny S and Hill C: Prediction of cancer outcome with microarrays: a multiple random validation strategy. Lancet 365: 488-492, 2005.

17. Ransohoff DF: Rules of evidence for cancer molecular-marker discovery and validation. Nat Rev Cancer 4: 309-314, 2004.

18. Simon R, Radmacher MD, Dobbin K and McShane LM: Pitfalls in the use of DNA microarray data for diagnostic and prognostic classification. J Natl Cancer Inst 95: 14-18, 2003.

19. Eden P, Ritz C, Rose C, Ferno M and Peterson C: 'Good Old' clinical markers have similar power in breast cancer prognosis as microarray gene expression profilers. Eur J Cancer 40: 1837-1841, 2004.
20. Singletary SE, Allred C, Ashley P, et al: Revision of the American Joint Committee on Cancer staging system for breast cancer. J Clin Oncol 20: 3628-3636, 2002.

21. Todd JH, Dowle C, Williams MR, et al: Confirmation of a prognostic index in primary breast cancer. Br J Cancer 56: 489-492, 1987.

22. Elston CW and Ellis IO: Pathological prognostic factors in breast cancer. I. The value of histological grade in breast cancer: experience from a large study with long-term follow-up. Histopathology 19: 403-410, 1991.

23. Hauser-Kronberger $\mathrm{C}$ and Dandachi N: Comparison of chromogenic in situ hybridization with other methodologies for HER2 status assessment in breast cancer. J Mol Histol 35: 647-653, 2004.

24. Goldhirsch A, Wood WC, Gelber RD, Coates AS, Thurlimann B and Senn HJ: Meeting highlights: updated international expert consensus on the primary therapy of early breast cancer. J Clin Oncol 21: 3357-3365, 2003.

25. Ravdin PM, Siminoff LA, Davis GJ, et al: Computer program to assist in making decisions about adjuvant therapy for women with early breast cancer. J Clin Oncol 19: 980-991, 2001.

26. Olivotto IA, Bajdik CD, Ravdin PM, et al: Population-based validation of the prognostic model ADJUVANT! for early breast cancer. J Clin Oncol 23: 2716-2725, 2005.

27. Bueno-de-Mesquita JM, Linn SC, Keijzer R, et al: Validation of 70-gene prognosis signature in node-negative breast cancer. Breast Cancer Res Treat 117: 483-495, 2009. 